\title{
Quality of life of children with nephrotic syndrome- development of a tool
}

Jacob $\mathrm{M}^{1}$, Mathew $\mathrm{E}^{2 *}$

*Corresponding author:

${ }^{2}$ Dr. Elsheba Mathew, Asst. Professor, Dept. of Community Medicine, Pushpagiri Hospital, Pushpagiri Institute of Medical Sciences \& Research Centre, Thiruvalla, Kerala

Email: elsheba.mathew@gmail.com ORCID

${ }^{1}$ Research Scholar, School of Behavioral Sciences

\section{Information about the article:}

Received: Jan. 17, 2019

Accepted: Feb. 20, 2019

Published online: Dec. 27, 2019

\section{Publisher}

Nepal Health Research Society, Bahundhara -6, Gokarnesowor Municipality, Kathmandu, Nepal

eISSN 2382-5545, ISSN 2676-1343 (Print)

(C) The Author(s). 2019

Content licensing: CC BY 4.0

\section{ABSTRACT}

\section{Background}

Quality of life is an individual's perception of their position of life in the context of their culture and value systems in which they live and, in their goals, expectations, standards and concerns. (WHO). Though various tools to measure the generic quality of life of paediatric clients are available, a disease specific tool that is culturally adaptive to assess the quality of life of children with nephrotic syndrome is unavailable. The aim of the study was to develop a valid and reliable tool to assess the quality of life of children with nephrotic syndrome.

\section{Materials and methods}

In-depth interview of twenty children with nephrotic syndrome and their mothers, review of literature and discussion with experts in health sector to formulate preliminary form of the tool. Tool is evaluated by 11 experts to ensure the content validity. Tool is then administered to 100 children with nephrotic syndrome. Item analysis was done to finalize the items in the scale and reliability estimated with split half technique $(r=0.93)$.

\section{Results}

Nephrotic Syndrome Paediatric Quality of Life (NSPQOL) assessment scale was finalized with 35 item using four-point rating scale.

\section{Conclusion}

The findings of the study suggest that the tool has potential for use as both a clinical as well as a research instrument

\section{Keywords}

Assessment tool, nephrotic syndrome, quality of life, school children 